\title{
An investigation on thermal and chemical behavior of jute/hemp/flax fiber reinforced woven composites and its hybrids
}

DOI : 10.36909/jer.ICCEMME.15753

\author{
${ }^{1}$ Vijay Chaudhary \\ 1*Partha Pratim Das \\ ${ }^{2,3}$ Rohit Sahu \\ ${ }^{3}$ Krovvidi Srinivas $\quad{ }^{4}$ Vijay Kumar Dwivedi \\ ${ }^{1}$ Department of Mechanical Engineering, Amity University Uttar Pradesh, Noida, Pin: \\ 201313, India, \\ ${ }^{2}$ Department of Mechanical Engineering, G. L Bajaj Institute of Technology and \\ Management, Greater Noida, Uttar Pradesh, India, Pin:201306 \\ ${ }^{3}$ Department of Mechanical Engineering, Delhi Technological University, Shahbad \\ Daulatpur, Rohini, New Delhi, Pin: 110042, India \\ ${ }^{4}$ Department of Mechanical Engineering IET, GLA University, Mathura, India \\ *Email: das1.parthapratim@gmail.com; Corresponding Author.
}

\begin{abstract}
Natural fiber has emerged as a viable alternative to synthetic fibers like glass, carbon, and Kevlar for the development of polymeric composites. Present study focused on Thermo-gravimetric analysis (TGA), Differential thermal analysis (DTA), and Fourier transform infrared spectroscopy (FTIR) of the reinforced fibers and developed composites. HR-X-Ray Diffraction of neat epoxy, jute, hemp, and flax fibers was also performed. For TGA, as the temperature increases up to $250^{\circ} \mathrm{C}$, thermal degradation of all composites is higher as compared to the neat epoxy. Addition of natural fibers as reinforcement with epoxy matrix affects the transmittance peaks between $1000-1500 \mathrm{~cm}^{-1}$ and $1608-1738 \mathrm{~cm}^{-1}$ in FTIR spectra. The peaks transmittance between $1000-1500 \mathrm{~cm}^{-1}$ represents the chemical compositions of the fibers (hemicellulose, cellulose, lignin, and pectin) which are the necessary part of plant fibers. In Xray diffraction, two sharp peaks appear at a diffraction angle of $21.4^{0}$ and $14.8^{0}$ for jute, hemp, and flax fibers. Peak at a diffraction angle (2Ө) of $26.3^{\circ}$ represents $\alpha$-cellulose and $14.26^{0}$ represents noncellulose material such as hemicellulose and lignin in fiber.
\end{abstract}

Keywords: FTIR, TGA, X-ray diffraction, hemicellulose, lignin, pectin, spectroscopy

\section{INTRODUCTION}


Natural fibers (Jute, hemp, sisal, linen, banana, flax, etc.) are eco-friendly and non-toxic, and can be used as a reinforcement to replace and reduce the use of synthetic fibers (glass, carbon, Kevlar ,aramid etc.) for manufacturing of polymeric materials.

Synthetic fibers are very harmful to the environment (Chaudhary et al., 2018b, 2018a; Das, Chaudhary, et al., 2020; Das et al., 2021). Natural fiber reinforced polymer composites are used natural fibers as reinforcement for manufacturing of polymeric composites (Bajpai et al., 2017; Chaudhary \& Ahmad, 2020). In polymer composites, reinforcement strengthens the composite and matrix surrounds the reinforced fibers.

Reinforced fibers are tightly bonded to the polymer matrix, and the resulting composite is strong enough to withstand up-to their specific strength (Das, Rao, et al., 2020; Das \& Chaudhary, 2020; Manral et al., 2020). Massive properties of developed composites like lightweight, high specific strength, traditional cellular structure, and solid acoustic and thermal insulation properties withstand them in various engineering applications. It is very important to predict how these composites will perform under various environmental conditions before using them. An engineer's ability to characterize these composites aids in the selection of the best composite for a given application. TGA, DTA, XRD, and FTIR are some of the experimental analysis used to study the thermal and chemical behavior of the developed composites. TGA is used to investigate the temperature-related alterations in composites' physical and chemical properties. TGA is often used to calculate the temperature at which the composites developed degrades (Guleria et al., 2017). For testing, powder samples of 5-20 mg are used. The TGA setup consists of a small electrically heated furnace and a weighing unit. As the sample in the oven is heated at a constant rate, the system continuously weighs it (Berthet et al., 2017; Dayo et al., 2017; Julkapli \& Akil, 2010). FTIR spectroscopy is employed, and the Fourier transformation is used as a technique to convert raw data from the spectroscope into image format. A graph of transmittance vs. wavenumber summarizes the spectroscopic results.(Essabir et al., 2016; Lomelí-Ramírez et al., 2014).

Study on TGA, XRD study, and FTIR spectroscopy of NFRPC has been carried out by various authors. (De Rosa, Kenny, et al., 2010) studied the chemical structure of the orka fibers using FTIR. The absorbance peak of orka fibers clearly showed the presence of chemical compositions such as cellulose, hemicellulose and lignin. Authors concluded that the absorbance peak between $3600 \mathrm{~cm}^{-1}$ to $3100 \mathrm{~cm}^{-1}$ corresponds to the $\mathrm{O}-\mathrm{H}$ stretching vibration and hydrogen bond of the hydroxyl group. The absorbance peaks at $1743 \mathrm{~cm}^{-1}$ correspond the carbonyl $\mathrm{C}=\mathrm{O}$ stretching vibration of carboxylic acid in lignin and $1384 \mathrm{~cm}^{-1}$ to $1243 \mathrm{~cm}^{-1}$ belongs to the $\mathrm{C}-\mathrm{O}$ stretching vibration of the acetyl group in lignin and hemicellulose component. Saha et al.(Saha et al., 2010) conducted X-RD and FTIR analysis of jute fibers. The authors concluded that jute fibers displayed cellulose crystallites justified by X-ray 
diffractograms and jute fibre FTIR spectra showed a strong peak of absorbance at 3200 to $3600 \mathrm{~cm}-1$, reflecting the hydrogen bond $\mathrm{O}-\mathrm{H}$ stretching.

This study focused on the HR-X-Ray diffraction of neat epoxy, jute, hemp, and flax fiber. Various tests such as TGA, DTA, and FTIR for neat epoxy, as well as all the developed composites, were undertaken in this present study the thermal and chemical behavior of NFRPCs.

\section{EXPERIMENTAL METHODS}

\section{Fibers and matrix}

Jute, hemp, and flax fibers were used to develop the polymer composites. J3P grade epoxy resin and universal 10000 grade hardener are employed as the polymer matrix.

\section{Processing Method}

All the samples of composites were fabricated by closed mod hand-lay-up technique. A mild steel closed mold with dimensions of $200 \times 200 \mathrm{~mm}$ was used. Each type of composite was made with a quarter $(25 \%)$ of a percent of fibers by weight. For hybrid composites same weight percentage of fibers were used. Abbreviations of developed composites used in this study are listed in Table 1.

Table 1. Abbreviations of the developed composites.

\section{Thermogravimetric}

\begin{tabular}{|c|c|}
\hline Abbreviation & Description \\
\hline J/Epoxy & Jute/epoxy \\
\hline H/Epoxy & Hemp/epoxy \\
\hline F/Epoxy & Flax/epoxy \\
\hline J/H/Epoxy & Jute/hemp/ epoxy \\
\hline H/F/Epoxy & Hemp/flax/ epoxy \\
\hline J/H/F/Epoxy & Jute/hemp/flax/epoxy \\
\hline
\end{tabular}

analysis (TGA)

TGA is an analytical tool that assesses the thermal stability of a material and its volatile component fraction by analyzing the shift in weight that occurs when a sample is heated at a constant rate. This method was performed by S11 Perkin Elmer Diamond TG/DTA setup in a nitrogen environment. Samples in solid pallets were examined in a nitrogen environment to a maximum temperature of $630{ }^{\circ} \mathrm{C}$ at the rate of $10{ }^{\circ} \mathrm{C} / \mathrm{min}$. The loss in weight was measured with an increase in temperature.

Differential thermal analysis (DTA) 
DTA was carried out using DTA S11 Perkin Elmer Diamond TG/DTA setup. Samples in solid pallet form were examined in a nitrogen environment to a maximum temperature of $630{ }^{\circ} \mathrm{C}$ at the rate of $10{ }^{0} \mathrm{C} / \mathrm{min}$. The heat absorbed or released was measured along with the increase in temperature.

\section{FTIR Spectroscopy}

The FTIR (Fourier transform infrared) spectrometer from Thermo Scientific was used to perform the infrared spectroscopy (Nicolet 380). Both composites containing natural fiber were crushed into extremely fine particles. The pallets were made by combining sample particles with $\mathrm{KBr}$ and then pressing them into a $1 \mathrm{~mm}$ thick disk, as shown in figure 1. SEM images of fibers and their natural fiber mats for the J/Epoxy, H/Epoxy, and F/Epoxy composites developed in Figure 2

Figure 1 Pallet of epoxy mixed

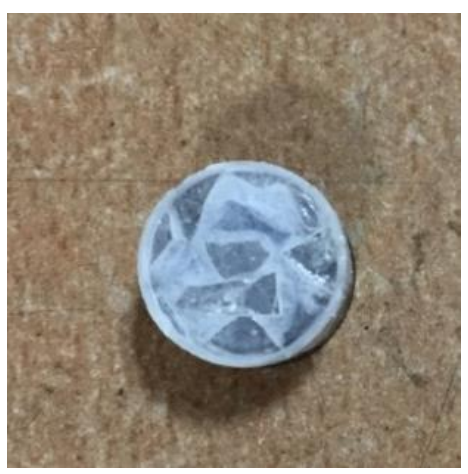

with $\mathrm{KBr}$.

\section{High Resolution XRD}

High resolution XRD was performed by D8 Discover HR-XRD. Neat epoxy, jute, hemp, and flax fiber were crushed into small particles. Diffraction intensity of neat epoxy, jute, hemp, and flax fiber was recorded at a diffraction angle $(2 \theta)$ of 5 to $65^{\circ}$ at a scan rate of $40 \mathrm{~min}$. 


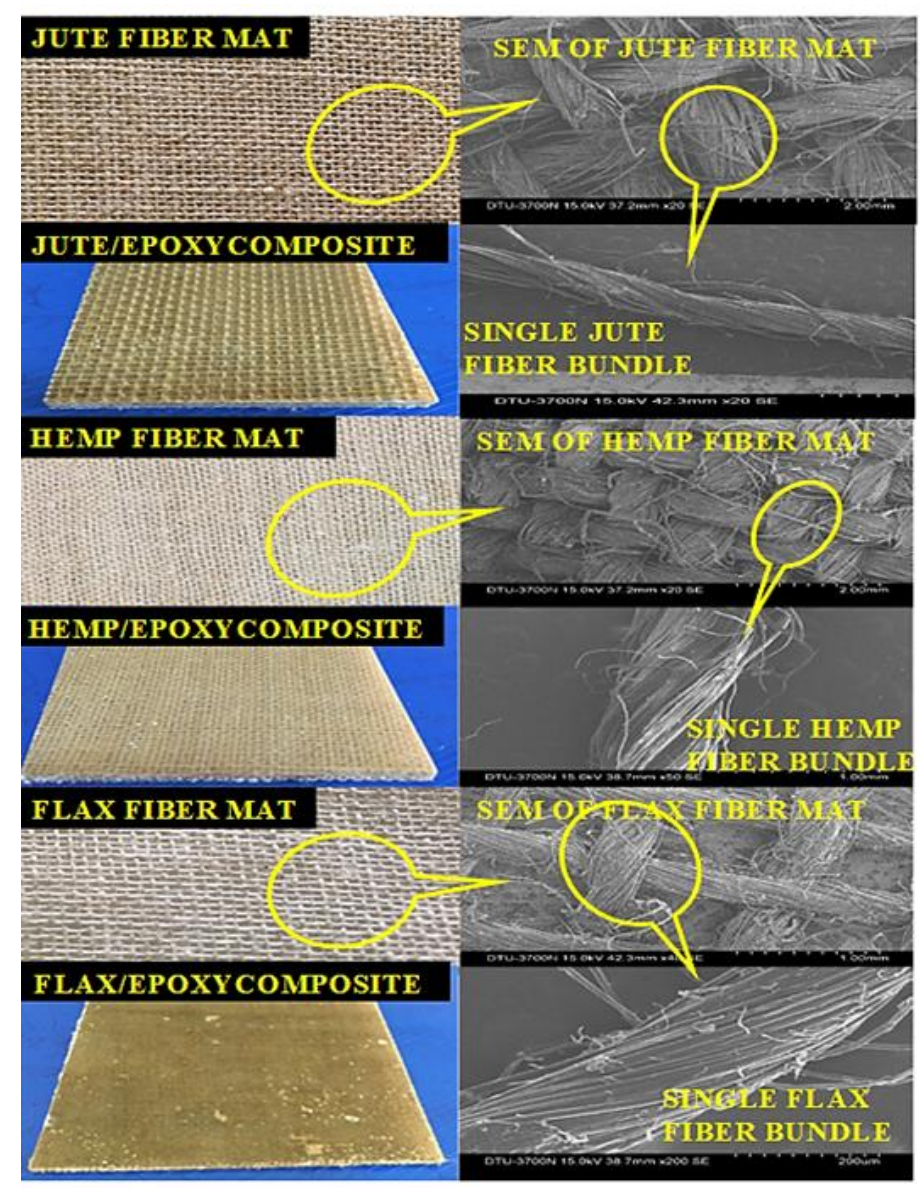

Figure 2. J/Epoxy, H/Epoxy and F/Epoxy composites and their SEM images.

\section{RESULT \& DISCUSSIONS}

\section{Thermogravimetric analysis (TGA)}

The control factor in the fabrication of polymeric materials is thermal stability. Thermogravimetric analysis was used to investigate the thermal stability of neat epoxy and all of the formed composites (TGA). The temperature range for the experiment was $35^{\circ} \mathrm{C}$ to $450^{\circ} \mathrm{C}$. The high-temperature degradation behavior of formed polymer composites was studied using the TGA curves obtained thus far. Figure 3 shows weight loss percentages versus degradation temperatures for neat epoxy, and all developed composites. Table 2 shows the weight loss up to $100^{\circ} \mathrm{C}, 200^{\circ} \mathrm{C}, 300$ to $400^{\circ} \mathrm{C}$ and the final residual left.

For all the composites developed, as the temperature increases upto $250^{\circ} \mathrm{C}$, thermal degradation of composites is higher as compared to neat epoxy. Initial degradation occurs between the temperature range of $35^{\circ} \mathrm{C}$ to $250^{\circ} \mathrm{C}$ because of vaporization of moisture content present in the fibers (De Rosa, Santulli, et al., 2010). From temperature $35^{\circ} \mathrm{C}$ to $250^{\circ} \mathrm{C}$, all the developed composites including neat epoxy showed an almost similar pattern of degradation. 
But after $250^{\circ} \mathrm{C}$, suddenly more degradation occured in all composites and neat epoxy. In composites, the initial rate of degradation is higher because of the decomposition of hemicellulose, cellulose, lignin and pectin present in jute, hemp and flax fibers(Guleria et al., 2017; Julkapli \& Akil, 2010; Revati et al., 2017) . For neat epoxy initially 0.82 wt. $\%$ of the original weight is reduced at $100^{\circ} \mathrm{C}$. As natural fibers are hydrophilic in nature, they absorb a large amount of water as compared to neat epoxy. At initial stage $\left(35{ }^{\circ} \mathrm{C}\right.$ to $\left.250^{\circ} \mathrm{C}\right)$, weight loss of neat epoxy is less than $8 \%$ while all the developed composites lost more than $8 \%$ of its original weight. But in the second stage, from temperature $250^{\circ} \mathrm{C}$ to $400^{\circ} \mathrm{C}$ all the developed composites degrades swiftly as well as neat epoxy and loses $70 \%$ of its original weight. In the $2^{\text {nd }}$ stage, the thermal degradation of neat epoxy is higher $(67.58 \%)$ as compared to all developed composites. In $2^{\text {nd }}$ stage degradation occurs due to the volatile content in the polymer matrix and debasement of epoxy polymer (Kumar et al., 2014). At temperature, above $250^{\circ} \mathrm{C}$, the composite structure showed lower degradation than neat epoxy. The thermal stability of the developed composites is higher as compared to the neat epoxy. This increased stability of composites compared to neat epoxy is due to improved fiber-matrix interaction. A similar study was conducted by Sreenivasan et al.(Sreenivasan et al., 2015). Authors studied weight loss of Sansevieriacylindrica/polyester composite under varying temperature with the help of thermogravimetric analysis. Authors concluded that major weight loss of the developed composite was noticed between $250^{\circ} \mathrm{C}$ to $400^{\circ} \mathrm{C}$ due to breakage of the internal structure of composite by thermal loading. The composite degradation at higher temperatures is protected by strong interfacial adhesion between the fiber-matrix interface.

At temperature $450^{\circ} \mathrm{C}$, the residual weight of neat epoxy is $7 \mathrm{wt} . \%$ of the original weight, present in the form of charcoal, carbon and ash content left. For the jute/epoxy composite, initial weight reduction is $2.32 \mathrm{wt}$. $\%$ of original weight from temperature 35 to $100^{\circ} \mathrm{C}$, that shows an increment in weight degradation as compared to neat epoxy. In the next phase $6.53 \mathrm{wt} . \%$ of the original weight is reduced at $200{ }^{\circ} \mathrm{C}$. The dominant degradation of $63.84 \mathrm{wt}$. $\%$ of original weight occurs at 310 to $400^{\circ} \mathrm{C}$. At a temperature of $499{ }^{\circ} \mathrm{C}$, final residual weight is $8.28 \mathrm{wt}$. \% of the original weight. For hemp/epoxy composite initially 3.48 wt. $\%$ of original weight degrades at $100^{\circ} \mathrm{C}$. At $200{ }^{\circ} \mathrm{C}, 5.8$ wt. $\%$ of the original weight is reduced for hemp/epoxy composite.

The extensive degradation of hemp/epoxy composite occurs at a temperature range of $290^{\circ} \mathrm{C}$ to $380^{\circ} \mathrm{C}$ which is 65.68 wt. $\%$ of the original weight. The final degradation occurs at a temperature of $422^{\circ} \mathrm{C}$ and the residue is 12.52 wt. \% of the original weight. For flax/epoxy composite, 2.38 wt. \% of the original weight is reduced at $100{ }^{\circ} \mathrm{C}$ that is almost similar to jute/epoxy composite. Degradation of 5.42 wt. \% of the original weight occurs at a temperature of $200{ }^{\circ} \mathrm{C}$ and $57.3 \mathrm{wt} . \%$ of original weight 
occurs at a temperature of $300{ }^{\circ} \mathrm{C}$ to $400{ }^{\circ} \mathrm{C}$. At $438{ }^{\circ} \mathrm{C}$, the final residue is $25 \mathrm{wt} . \%$ of the original weight. The final residue contains carbon content, ash content and other carbon-based material.

For jute/hemp/epoxy composite, 2.71 wt. $\%$ of the original weight is reduced at $100{ }^{0} \mathrm{C}$. Second degradation of 2.31 wt. $\%$ of original weight occurs at a temperature of $200{ }^{\circ} \mathrm{C}$. The major weight reduction occurs at a temperature of 320 to $410{ }^{\circ} \mathrm{C}$, that is 46.72 wt. \% of the original weight. At 438 ${ }^{0} \mathrm{C}$, the final residue is $38 \mathrm{wt} \%$ of the original weight. For hemp/flax/epoxy composite, thermal degradation curve shows that the initial weight loss up to $100{ }^{\circ} \mathrm{C}$ is $3.73 \mathrm{wt} . \%$ of the original weight and this is almost similar to the hemp/epoxy composite. The second degradation starts after $200{ }^{\circ} \mathrm{C}$ and the loss of mass is $6.64 \mathrm{wt}$. \% of the original weight. The extensive degradation of $61.6 \mathrm{wt} \%$ of original weight occurs between $300^{\circ} \mathrm{C}$ to $400^{\circ} \mathrm{C}$. Final mass residue at $424^{\circ} \mathrm{C}$ is $6.86 \mathrm{wt} \%$ of the original weight. Thermal degradation curve of jute/hemp/flax/epoxy composite shows that 4.98 wt. \% of the original weight was lost up to a temperature of $100{ }^{\circ} \mathrm{C}$. Further degradation of 7.95 wt. \% of original weight occurs up to a temperature of $200^{\circ} \mathrm{C}$. The Final mass residue is $17.33 \mathrm{wt}$. $\%$ of original weight containing charcoal and ash content. TGA of $\mathrm{J} / \mathrm{H} / \mathrm{F} /$ Epoxy composites shows that the weight loss between the temperature range $\left(200\right.$ to $\left.400^{\circ} \mathrm{C}\right)$ occurs due to the decomposition of hemicellulose, cellulose, lignin and pectin present in jute, hemp and flax fibers.

Table 2 Thermal degradation(TD) of composites at different temperature range.

\begin{tabular}{|c|c|c|c|c|}
\hline \multirow[b]{2}{*}{ Composites } & \multicolumn{4}{|c|}{ Weight Loss(\%) } \\
\hline & Upto $100^{\circ} \mathrm{C}$ & 100 to $250^{\circ} \mathrm{C}$ & $250^{\circ} \mathrm{C}$ to $400^{\circ} \mathrm{C}$ & Final residual \\
\hline Neat epoxy & 0.820 & 6.318 & 67.580 & 7.000 \\
\hline Jute/Epoxy & 2.324 & 6.534 & 63.841 & 8.280 \\
\hline Hemp/Epoxy & 3.486 & 5.809 & 65.680 & 12.510 \\
\hline Flax/Epoxy & 2.385 & 5.424 & 57.300 & 25.000 \\
\hline Jute/Hemp/Epoxy & 2.710 & 2.312 & 46.720 & 38.000 \\
\hline Hemp/Flax/Epoxy & 3.740 & 6.640 & 61.600 & 6.860 \\
\hline Jute/Hemp/Flax/Epoxy & 4.980 & 7.950 & 64.200 & 7.330 \\
\hline
\end{tabular}




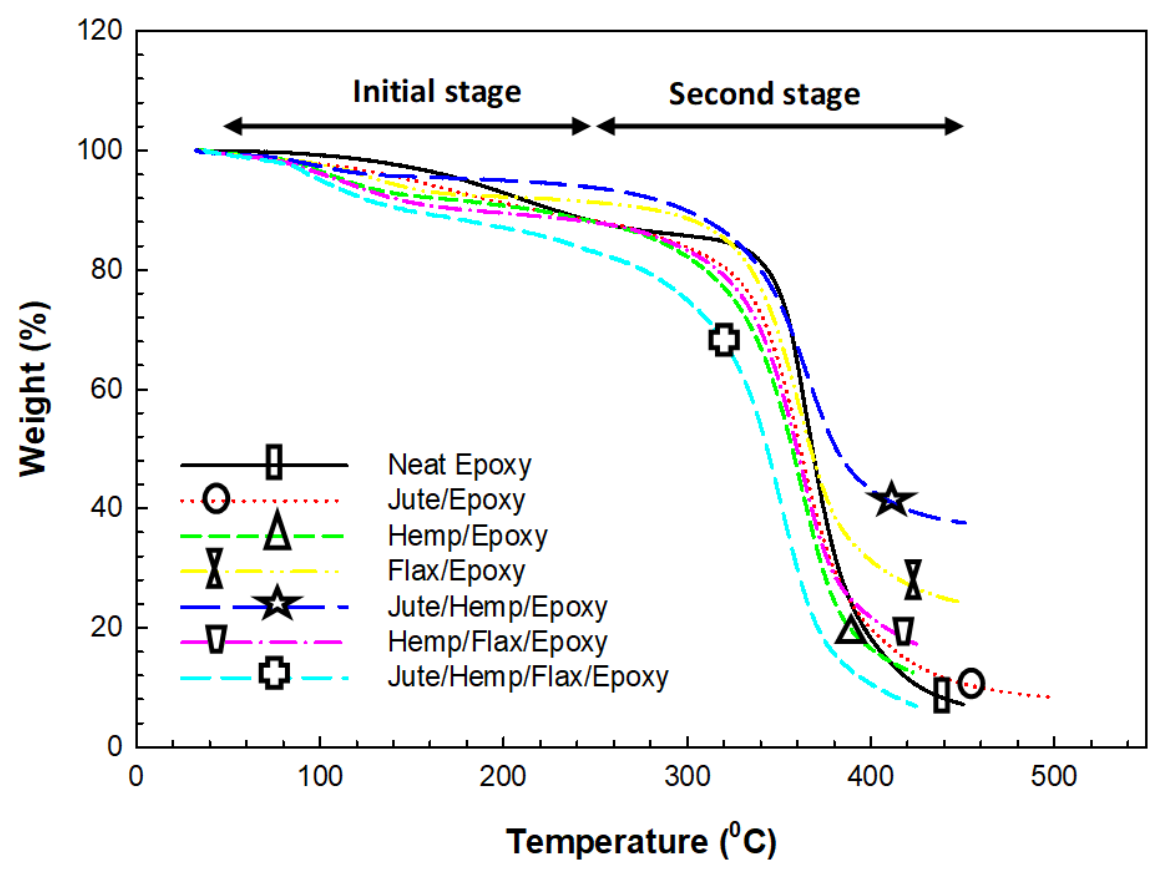

Figure 3 Thermogravimetric analysis of neat epoxy and composites.

\section{Differential thermal analyzer (DTA)}

The differential thermal analyzer is used to determine the nature of reaction during polymerization (either endothermic or exothermic). The temperature range used for the analysis is $35-450{ }^{\circ} \mathrm{C}$. Figure 4 shows DTA results of developed composites with neat epoxy resin.

DTA curve indicates the direction of reactions which may be either exothermic or endothermic.

Table 3 shows the amount of heat absorbed and the softening temperature of the developed composites. Results showed that all the developed composites absorbed heat with an increase in temperature. The maximum amount of heat absorption at a glass transition temperature of jute/epoxy composite showed a better heat-absorbing capacity than other developed composites. H/Epoxy and H/F/Epoxy composites absorbed almost equal heat of $30 \mathrm{~mW} \backslash \mathrm{mg}$ and $30.83 \mathrm{~mW} \backslash \mathrm{mg}$ at glass transition temperature of $357^{\circ} \mathrm{C}$ and $356.2^{\circ} \mathrm{C}$. J/H/Epoxy and $\mathrm{J} / \mathrm{H} / \mathrm{F} /$ Epoxy composites absorbed the heat of $17.02 \mathrm{~mW} \backslash \mathrm{mg}$ and 28.33 $\mathrm{mW} \backslash \mathrm{mg}$ at a glass transition temperature $\left(\mathrm{T}_{\mathrm{g}}\right)$ of $372.9{ }^{\circ} \mathrm{C}$ and $354{ }^{\circ} \mathrm{C}$ respectively. 


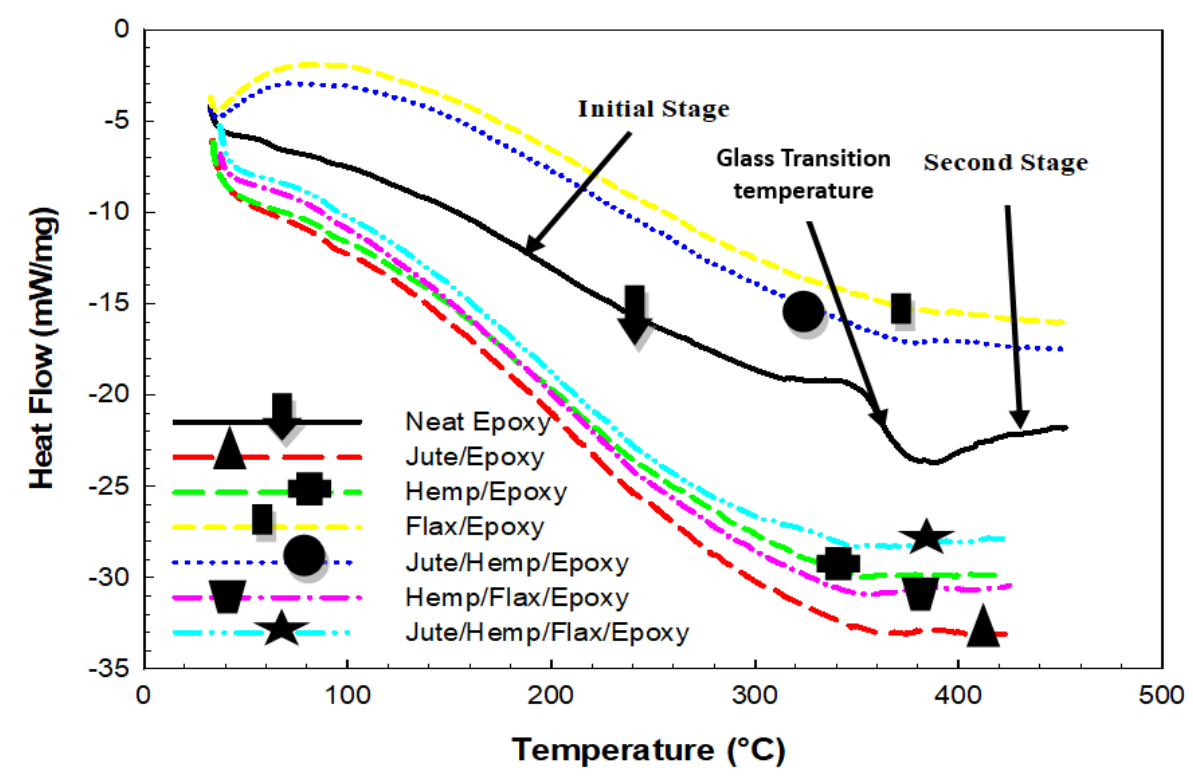

Figure 4 Differential thermal analysis of neat epoxy and composites.

Table 3 Heat absorbed by the composites at Glass Transition Temperature $\left(\mathrm{T}_{\mathrm{g}}\right)$.

\begin{tabular}{|c|c|c|}
\hline Composites & $\begin{array}{c}\text { Maximum heat absorbed } \\
(\mathbf{m W} / \mathbf{m g})\end{array}$ & $\begin{array}{c}\text { Glass transition } \\
\text { temperature } \\
\left({ }^{\mathbf{0}} \mathbf{C}\right)\end{array}$ \\
\hline Neat epoxy & 17.33 & 316 \\
\hline Jute/epoxy & 33.02 & 357.3 \\
\hline Hemp/epoxy & 30.0 & 357.0 \\
\hline Flax/epoxy & 15.42 & 378.0 \\
\hline Jute/hemp/epoxy & 17.08 & 372.9 \\
\hline Hemp/flax/epoxy & 30.83 & 356.2 \\
\hline Jute/hemp/flax/epoxy & 28.33 & 354.0 \\
\hline
\end{tabular}

Fourier transform infrared spectroscopy (FTIR)

Infrared transmittance peaks recorded for the developed composites are compared with neat epoxy as shown in figure 5. Jute, hemp and flax fibers are plant-based fibers having a chemical composition consisting of cellulose, hemicellulose, lignin and pectin(Mwaikambo \& Ansell, 2002). With Addition of natural fibers (jute, hemp, and flax) with epoxy resin changes the bonding structure at the mating surface of fibers and matrix which influences the infrared transmittance peaks at different wavenumbers. Absorbance peaks between the wavenumber of 500-4000 $\mathrm{cm}^{-1}$ are analyzed. All the 
developed composite shows a similar pattern of wavenumbers with different values of absorbance peaks. The absorbance peaks between the wavenumber of $1000-1500 \mathrm{~cm}^{-1}$ which indicate the presence of hemicellulose, cellulose, lignin, and pectin which are the important constituent part of natural (plant) fibers(Mwaikambo \& Ansell, 2002). The FTIR spectra of J/Epoxy composite shows the clear fluctuation in the intensity of peak between the wavenumber of $1608 \mathrm{~cm}^{-1}$ to $1738 \mathrm{~cm}^{-1}$, which indicates the presence of fatty acids in jute fibers as compared to hemp and flax fibers. Peaks between the wavenumber of $2927 \mathrm{~cm}^{-1}$ to $3427 \mathrm{~cm}^{-1}$ seen in all developed composites show the formation of hydrogen bonding and presence of hydroxyl group in all the developed composites (Sgriccia et al., 2008). Absorbance peaks of neat epoxy between the wavenumber of $1000-1500 \mathrm{~cm}^{-1}$ are absent, which shows the absence of hemicellulose, cellulose, lignin, and pectin. The absorbance peak of neat epoxy between the wavenumber of $3200 \mathrm{~cm}^{-1}$ to $3600 \mathrm{~cm}^{-1}$ indicates the hydrogen bonding and presence of hydroxyl groups(Sawpan et al., 2011). The various author carried out their study on the FTIR spectroscopy of natural fiber reinforced polymer (FRP) composites. Mwaikambo and Ansell(Mwaikambo \& Ansell, 2002) experimentally studied the FTIR spectra of jute, hemp, sisal \& kapok fibers. Authors concluded that the absorbance peak between $1000 \mathrm{~cm}^{-1}$ to $1500 \mathrm{~cm}^{-1}$ indicates the presence of hemicellulose and lignin in plant-based fibers and absorbance peak between the wavenumber of $3200 \mathrm{~cm}^{-1}$ to $3600 \mathrm{~cm}^{-1}$ indicates the hydrogen bonding and the presence of hydroxyl groups. Sgriccia et al.(Sgriccia et al., 2008) investigated the FTIR spectrum of hemp and kanaf fibers. Authors concluded that the lignin peak at a wavenumber of $1500 \mathrm{~cm}^{-1}$ is present in kenaf fibers and $\mathrm{CH}$ stretch is also present at a wavenumber of $2900 \mathrm{~cm}^{-1}$ in kenaf and hemp fibers. Sawpan et al.(Sawpan et al., 2011) investigated the FTIR spectra of hemp fiber. Authors concluded that transmittance peak at a wavenumber of $3410 \mathrm{~cm}^{-1}$ shows hydrogen bonding and presence of hydroxyl groups. Satish kumara et al.(Sathishkumar et al., 2013) investigated the FTIR spectrum of sansevieria fiber. Authors concluded that the transmittance peak between the 400 to $1500 \mathrm{~cm}^{-1}$ wavenumber indicates the compositions dependent on plant fiber (cellulose, hemicellulose, and lignin) and the sharp peak between the $3100 \mathrm{~cm}^{-}$ ${ }^{1}$ to $3600 \mathrm{~cm}^{-1}$ wavenumber reflects the bonding of hydrogen as well as the presence of hydroxyl groups. 


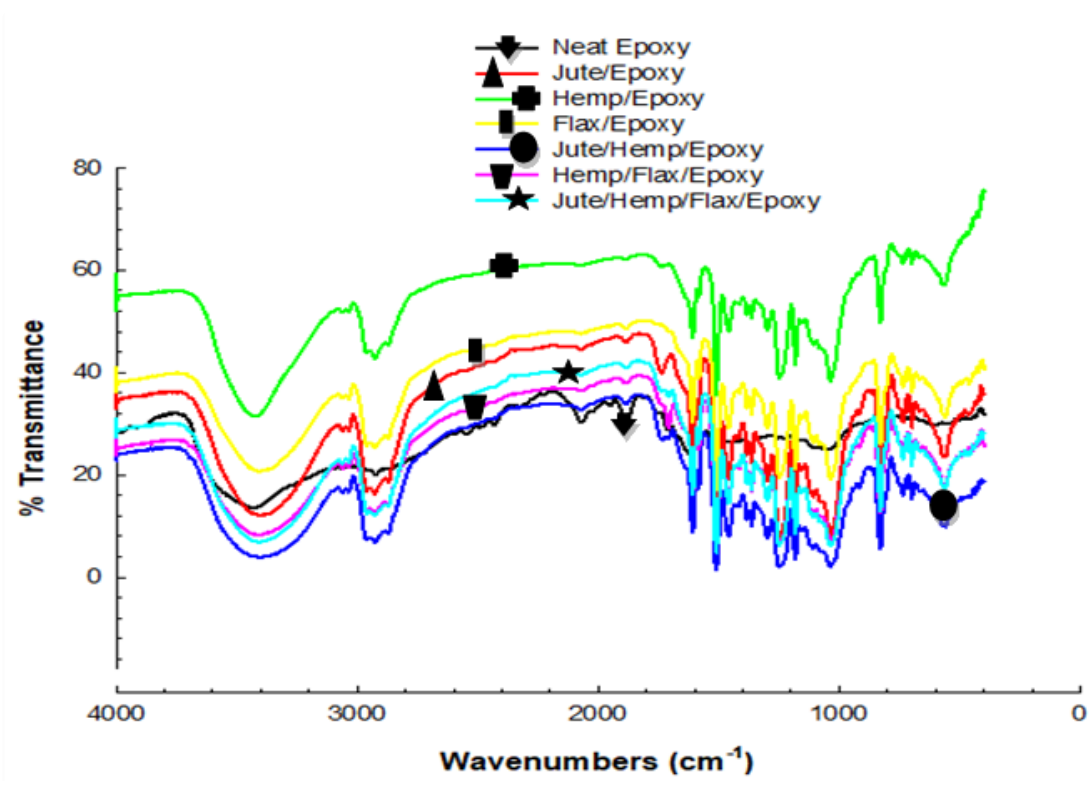

Figure 5 FTIR spectra of neat epoxy and composites.

\section{High Resolution X-Ray Diffraction (HR-XRD)}

Figure 6 shows the X-Ray Diffractograms of natural fibers and neat epoxy. The pattern of diffraction angle with different intensities is similar for jute, hemp, and flax fibers. The same pattern X-ray diffraction was recorded by bajpai et al.(Bajpai et al., 2013) for grevia optiva, nettle and sisal. It is observed from the diffractograms of jute, hemp, and flax fibers that there are two major crystalline peaks occur for each natural fiber. The primary largest crystalline peak occurs at a diffraction angle of $21.4^{0}$ and a second sharp peak of $14.8^{\circ}$ for jute, hemp, and flax fibers. For neat epoxy, a single and clear peak was observed at a diffraction angle $(2 \Theta)$ of $17.5^{\circ}$ as a clear indication of more crystalline material. If the material is amorphous in nature with a high content of its constituent materials such as cellulose, hemicellulose, lignin, and pectin then the peaks in the diffractograms occurs with low intensity and therefore the sharpness of the peak reduces and become filthy(Jayaramudu et al., 2010). Various author carried out their study on the X-ray diffraction analysis of natural fiber reinforced polymer composites. Sawpan et al.(Sawpan et al., 2011) performed XRD analysis of hemp fiber. Authors concluded that the hemp fiber showed the sharp peak of cellulose at a diffraction angle $(2 \theta)$ of $22^{\circ}$. Satish kumar et al. (Sathishkumar et al., 2013) investigated the X-ray diffractograms of sansevieria fiber. Authors concluded that two diffraction peaks found at a diffraction angle $(2 \theta)$ of $26.3^{\circ}$ and $14.26^{\circ}$. The peak at a diffraction angle $(2 \Theta)$ of $26.3^{0}$ represents of $\alpha$-cellulose and $14.26^{\circ}$ represents noncellulose material such as hemicellulose and lignin in a natural fiber. 


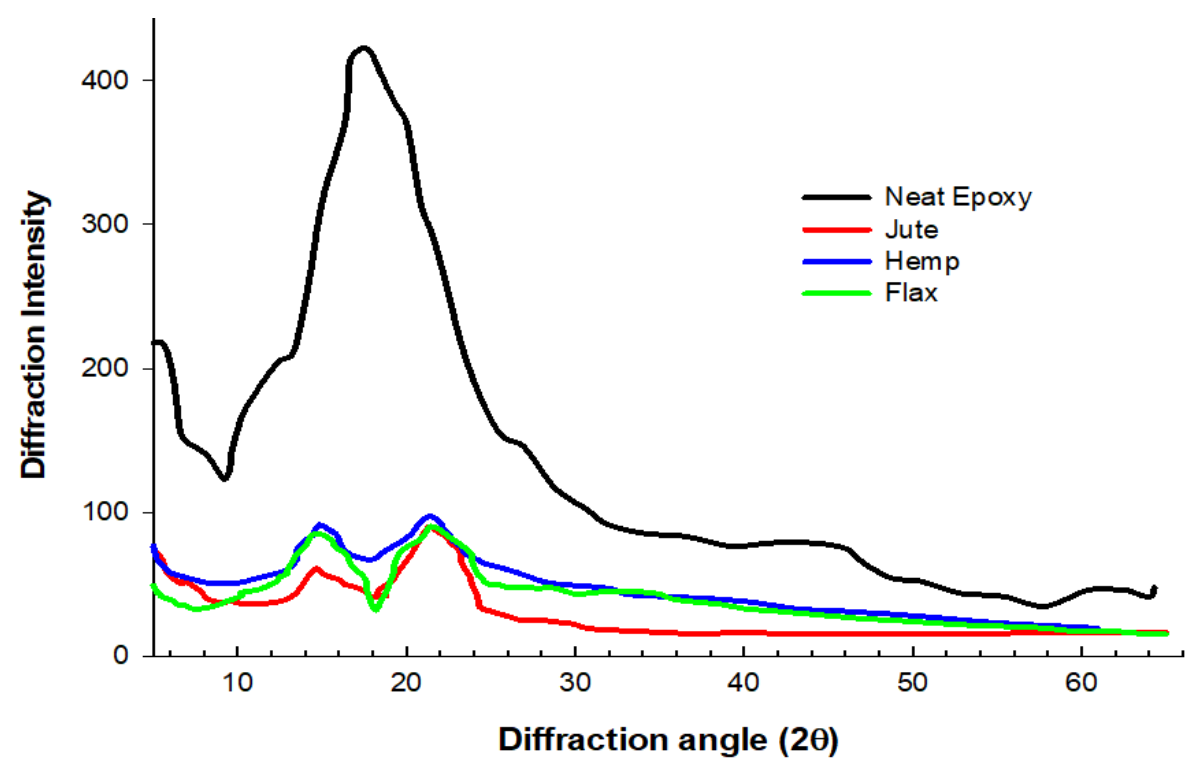

Figure 6 X-ray diffraction spectra of neat epoxy, jute, hemp, and flax fibers.

Percentage of crystallinity and crystallinity index was calculated using the given equations:

$$
\begin{aligned}
& \text { Percentage of Crystallinity }=\frac{I_{21}}{I_{21}+I_{14}} \times 100 \\
& \text { Crystallinity Index }=\frac{I_{21-} I_{14}}{I_{21}} \times 100
\end{aligned}
$$

Where $\mathrm{I}_{21}$ and $\mathrm{I}_{14}$ are the corresponding crystalline and amorphous diffraction peaks near to the 21 and 14 angles (2 Theta). For neat epoxy, jute, hemp and flax, the percentage of crystallinity and crystallinity index are shown in table 4.

XRD analysis shows that the fabricated composites are neither pure crystalline nor pure amorphous in nature and therefore, these are semi-crystalline in nature. Crystallinity index indicates the amount of cellulose present in the developed polymer composites (Sawpan et al., 2011). For a higher value of crystallinity index, more would be the cellulose content in the fiber (Reddy et al., 2013; Seki et al., 2013). The crystallinity index of flax fiber is 6.4 , which is lower than jute and hemp fiber. A lower value of the crystallinity index of flax fiber indicates the lower percentage of cellulose as compared to jute and hemp fiber. The crystallinity index of jute fiber is $59 \%$, which is higher in comparison to hemp and flax fiber. According to the higher crystallinity index, jute fiber is more crystalline in comparison to hemp and flax fiber. 
Table $4 \%$ crystallinity and crystallinity index of the jute, hemp, \& flax fiber.

\begin{tabular}{|c|c|c|}
\hline Sample & \% of Crystallinity & \% of crystallinity Index \\
\hline Jute & 59.2 & 31.2 \\
\hline Hemp & 52.2 & 6.4 \\
\hline Flax & 51.6 & 8.57 \\
\hline
\end{tabular}

\section{CONCLUSIONS}

TGA and FTIR spectroscopy of all developed composites, as well as X-ray diffraction of neat epoxy and natural fibers(jute, hemp, and flax), were investigated in this work. The following are some of the notable results from this investigation:

1. Temperature range used for thermogravimetric analysis was $35^{\circ} \mathrm{C}$ to $450^{\circ} \mathrm{C}$. For all the developed composites, with an increase in temperature upto $250^{\circ} \mathrm{C}$, thermal degradation of composites is higher as compared to neat epoxy.

2. In TGA, initial degradation occurs between the temperature ranges of $35^{\circ} \mathrm{C}$ to $250^{\circ} \mathrm{C}$, which is because of the vaporization of moisture present in the fibers.

3. Addition of natural fibers with resin (epoxy) also the influenced infrared transmittance peaks at different wavenumbers in FTIR spectrum in comparison to FTIR spectra of neat epoxy.

4. In FTIR spectra, the absorbance peaks between the wavenumber of $1000-1500 \mathrm{~cm}^{-1}$ clearly indicate the presence of hemicellulose, cellulose, lignin, and pectin which are a necessary part of plant-based fibers. Peaks between the wavenumber of $2927 \mathrm{~cm}^{-1}$ to $3427 \mathrm{~cm}^{-1}$ represent the formation of hydrogen bonding and presence of hydroxyl group in all the developed composites and neat epoxy.

5. In X-ray diffractor-grams, two major peaks occurred at a diffraction angle of $21.4^{0}$ and a second sharp peak of $14.8^{0}$ for jute, hemp, and flax fibers. But, in case of neat epoxy, a single and clear peak was observed at a diffraction angle $(2 \Theta)$ of $17.5^{\circ}$.

6. Two major peaks of jute, hemp and flax fiber at a diffraction angle of $21.4^{0}$ and $14.8^{0}$ represent the presence of chemical compositions for plant-based fibers like hemicellulose and $\alpha$-cellulose but the single peak of neat epoxy justified the absence of hemicellulose, lignin and pectin.

\section{REFERENCES}

Bajpai, P. K., Ahmad, F., Chaudhary, V., Martínez, L. M. T., Kharissova, O. V., \& Kharisov, B. I. (2017). Processing and characterization of bio-composites. Handbook of Ecomaterials, 1-18.

Bajpai, P. K., Singh, I., \& Madaan, J. (2013). Tribological behavior of natural fiber reinforced PLA composites. Wear, 297(1-2), 829-840.

Berthet, M.-A., Mayer-Laigle, C., Rouau, X., Gontard, N., \& Angellier-Coussy, H. (2017). Sorting natural fibres: A way to better understand the role of fibre size polydispersity on the mechanical properties of biocomposites. Composites Part A: Applied Science and Manufacturing, 95, 12-21.

Chaudhary, V., \& Ahmad, F. (2020). A review on plant fiber reinforced thermoset polymers for structural and frictional composites. Polymer Testing, 106792. 
Chaudhary, V., Bajpai, P. K., \& Maheshwari, S. (2018a). An investigation on wear and dynamic mechanical behavior of jute/hemp/flax reinforced composites and its hybrids for tribological applications. Fibers and Polymers, 19(2), 403415.

Chaudhary, V., Bajpai, P. K., \& Maheshwari, S. (2018b). Studies on mechanical and morphological characterization of developed jute/hemp/flax reinforced hybrid composites for structural applications. Journal of Natural Fibers, 15(1), $80-97$.

Das, P. P., \& Chaudhary, V. (2020). Tribological and dynamic mechanical analysis of bio-composites: A review. Materials Today: Proceedings, 25, 729-734.

Das, P. P., Chaudhary, V., \& Mishra, S. (2021). Emerging Trends in Green Polymer Based Composite Materials: Properties, Fabrication and Applications. In Graphene Based Biopolymer Nanocomposites (pp. 1-24). Springer.

Das, P. P., Chaudhary, V., \& Motha, S. J. (2020). Fabrication and Characterization of Natural Fibre Reinforced Polymer Composites: A Review. Available at SSRN 3569437.

Das, P. P., Rao, G. S., Mussada, E. K., Rao, G. B., Sharma, B. P., \& Vates, U. K. (2020). Fabrication and Tensile Testing of DHAK Fiber Reinforced Polyester Composites. In Advances in Production and Industrial Engineering (pp. 53-61). Springer.

Dayo, A. Q., Gao, B., Wang, J., Liu, W., Derradji, M., Shah, A. H., \& Babar, A. A. (2017). Natural hemp fiber reinforced polybenzoxazine composites: Curing behavior, mechanical and thermal properties. Composites Science and Technology, 144, 114-124.

De Rosa, I. M., Kenny, J. M., Puglia, D., Santulli, C., \& Sarasini, F. (2010). Morphological, thermal and mechanical characterization of okra (Abelmoschus esculentus) fibres as potential reinforcement in polymer composites. Composites Science and Technology, 70(1), 116-122.

De Rosa, I. M., Santulli, C., \& Sarasini, F. (2010). Mechanical and thermal characterization of epoxy composites reinforced with random and quasi-unidirectional untreated Phormium tenax leaf fibers. Materials \& Design (19802015), 31(5), 2397-2405.

Essabir, H., Bensalah, M. O., Rodrigue, D., Bouhfid, R., \& Qaiss, A. (2016). Structural, mechanical and thermal properties of bio-based hybrid composites from waste coir residues: Fibers and shell particles. Mechanics of Materials, 93, 134-144.

Guleria, A., Singha, A. S., \& Rana, R. K. (2017). Preparation of starch-based biocomposites reinforced with mercerized lignocellulosic fibers: Evaluation of their thermal, morphological, mechanical, and biodegradable properties. International Journal of Polymer Analysis and Characterization, 22(7), 595-609.

Jayaramudu, J., Guduri, B. R., \& Rajulu, A. V. (2010). Characterization of new natural cellulosic fabric Grewia tilifolia. Carbohydrate Polymers, 79(4), 847-851.

Julkapli, N. M., \& Akil, H. M. (2010). Thermal properties of kenaf-filled chitosan biocomposites. Polymer-Plastics Technology and Engineering, 49(2), 147-153.

Kumar, S. S., Duraibabu, D., \& and Subramanian, K. (2014). Studies on mechanical, thermal and dynamic mechanical properties of untreated (raw) and treated coconut sheath fiber reinforced epoxy composites. Materials \& Design, 59, 63-69.

Lomelí-Ramírez, M. G., Kestur, S. G., Manríquez-González, R., Iwakiri, S., de Muniz, G. B., \& Flores-Sahagun, T. S. (2014). Bio-composites of cassava starch-green coconut fiber: Part II-Structure and properties. Carbohydrate Polymers, 102, 576-583.

Manral, A., Ahmad, F., \& Chaudhary, V. (2020). Static and dynamic mechanical properties of PLA bio-composite with hybrid reinforcement of flax and jute. Materials Today: Proceedings, 25, 577-580. 
Mwaikambo, L. Y., \& Ansell, M. P. (2002). Chemical modification of hemp, sisal, jute, and

kapok fibers by alkalization. Journal of Applied Polymer Science, 84(12), 2222-2234.

Reddy, K. O., Maheswari, C. U., Shukla, M., Song, J. I., \& Rajulu, A. V. (2013). Tensile and structural characterization of alkali treated Borassus fruit fine fibers. Composites Part B: Engineering, 44(1), 433-438.

Revati, R., Majid, M. A., Ridzuan, M. J. M., Normahira, M., Nasir, N. M., \& Gibson, A. G. (2017). Mechanical, thermal and morphological characterisation of 3D porous Pennisetum purpureum/PLA biocomposites scaffold. Materials Science and Engineering: C, 75, 752-759.

Saha, P., Manna, S., Chowdhury, S. R., Sen, R., Roy, D., \& Adhikari, B. (2010). Enhancement of tensile strength of lignocellulosic jute fibers by alkali-steam treatment. Bioresource Technology, 101(9), 3182-3187.

Sathishkumar, T. P., Navaneethakrishnan, P., Shankar, S., \& Rajasekar, R. (2013). Characterization of new cellulose sansevieria ehrenbergii fibers for polymer composites. Composite Interfaces, 20(8), 575-593.

Sawpan, M. A., Pickering, K. L., \& Fernyhough, A. (2011). Effect of various chemical treatments on the fibre structure and tensile properties of industrial hemp fibres. Composites Part A: Applied Science and Manufacturing, 42(8), $888-895$.

Seki, Y., Sarikanat, M., Sever, K., \& Durmuşkahya, C. (2013). Extraction and properties of Ferula communis (chakshir) fibers as novel reinforcement for composites materials. Composites Part B: Engineering, 44(1), 517-523.

Sgriccia, N., Hawley, M. C., \& Misra, M. (2008). Characterization of natural fiber surfaces and natural fiber composites. Composites Part A: Applied Science and Manufacturing, 39(10), 1632-1637.

Sreenivasan, V. S., Rajini, N., Alavudeen, A., \& Arumugaprabu, V. (2015). Dynamic mechanical and thermogravimetric analysis of Sansevieria cylindrica/polyester composite: Effect of fiber length, fiber loading and chemical treatment. Composites Part B: Engineering, 69, 76-86. 